informed debate on the balance between local services, national services, and scientific activities.

GORDON MACPHERSON

Deputy editor, $\boldsymbol{B} M \mathcal{F}$

\section{School dinners}

When compulsory education began in Britain in 1880 school dinners were provided by volunteers. Later it became compulsory for local authorities to provide milk and dinners of specific nutritional standard for all schoolchildren who wanted them. But since 1984 much of the central control has been relinquished, and local authorities are now responsible for the cost and nutritional standard of school meals. The only statutory requirement is that they provide meals to children entitled to free ones, and this system is about to be replaced. In 1984 half of the school population of 6.6 million had school meals, and for $17 \%$ they were free (Department of Education and Science, unpublished census). Do school meals matter any more or are they an anachronism left from a time when absolute poverty was much more widespread?

Nutritionally the primary school years are quiet and interest focuses on children at secondary school, particularly as they pass through puberty and adolescence. Both sexes experience a growth spurt; in girls it is earlier, peaking at around the menarche, and substantial extra fat is deposited; while boys grow taller and develop bigger bones clothed more in muscle than fat. Faster growth requires more food, bones need more calcium, and the menarche and muscles need more iron-the nutritional implications are clear.

Food is much more, however, than just a purveyor of nutrients. In all societies eating together is a vehicle of social interaction, and this probably needs to be taught at school because just as with learning to cross the road and sex education we cannot assume that all parents will take it on. The school meal could also illustrate current concepts of healthy eating, although, just like ways of teaching mathematics, these concepts change as much in response to fashion as to objective evidence. Several schemes have combined the school meals service and other school or health departments, such as home economics, science, and health education. ${ }^{12}$

So it is possible to weave a plausible nutritional, social, and educational argument that school meals are beneficial-but is there any objective evidence of recent benefit in Britain? A 1983 survey showed that generally total nutrient intakes of British children were above the recommended dietary allowances, although in common with people of all ages energy intakes were lower. ${ }^{3}$ The children exceeded the height and weight standards for age, and the survey found no great differences in the nutrient intakes of children in different social circumstances. The quantity was thus reasonable, but the quality of the children's diet might cause concern. Over one fifth had an intake of energy from fat of over $40 \%$, when current thinking is that it should not exceed $35 \% .{ }^{45}$ Many of the children ate many chips, crisps, cakes, and biscuits.

School dinners provided about a third of the children's total energy intake and were generally satisfactory, although they gave two points for concern. Firstly, older schoolchildren, particularly girls who ate lunch at cafés and the like rather than at school, had low intakes of many nutrients both at lunchtime and in the day as a whole; their iron intakes were especially vulnerable. Secondly, the older children who qualified for free school meals got more of their total energy intake from school dinners than was the case for children who paid. The differences were not large but demanded caution-for example, among girls aged 14 and 15 those paying consumed $8 \cdot 1 \mathrm{MJ}(1930 \mathrm{kcal})$ daily and got $3 \cdot 1 \mathrm{MJ}(740 \mathrm{kcal})(35 \%)$ from school dinners; those receiving free school dinner consumed $8.6 \mathrm{MJ}(2050 \mathrm{kcal})$ daily and got $3.7 \mathrm{MJ}(880 \mathrm{kcal})(43 \%)$ from school dinners. Does this mean that underprivileged older schoolgirls depend more on their school dinners than more fortunate children and that therefore school dinners are an essential part of educational medicine? Or does it mean that older schoolgirls who have free meals eat more at school and so their total intake is higher than that of more fortunate children? From the data provided by the survey we can accept neither interpretation.

The Nutrition Surveillance Committee of the Department of Health and Social Security has encouraged and supported assessments of the nutritional value of school milk. ${ }^{6}$ Children aged 7 or 8 from large families and attending schools where many pupils qualified for free school meals were studied over six terms. Those receiving free milk gained more height (a significant gain but only a $2.93 \mathrm{~mm}$ difference) and more weight (a $130 \mathrm{~g}$ difference, which was not significant) than the control group-hardly resounding evidence that free school milk is essential for underprivileged primary schoolchildren. Would it be possible to have similarly objective evidence on school dinners? I am sure that other measures of nutritional state apart from growth and dietary intake would require assessment-for example, if iron intakes in adolescent girls eating out of school are low we need to know their haemoglobin concentrations.

My own belief is that school dinners are important in the nutritional, educational, and social environment of schoolchildren-but I cannot marshall convincing evidence on health. Nevertheless, even if immediate nutritional benefit cannot be shown I regard the educational and social role of school meals as important. Mothers with reasonable ideas on their own nutritional welfare are usually receptive to informed views on the nutritional welfare of their children; I believe that their own ideas can be moulded and modified by example at school.

Of course, the children need to consume the school dinner for it to be of any value. Fast food chains attract schoolchildren, and we may have something to learn from their marketing methods. Hamburgers are here to stay so let's have lower fat, low salt ones at school with wholemeal buns and thick chips (they take up less fat). Many (not all) of the commercial weaning foods available in Britain are nutritionally sound and enjoyed by their consumers; could the manufacturers produce foods for older children? The food industry should be seen as a valuable resource to be used effectively in promoting school health, which is not to delegate our ideas on the nutritional adequacy of school meals. In my view it is unfortunate that nutritional guidelines are no longer specified by the Department of Education and Science, but some education authorities-for example, Birmingham 7 - have set up their own. When evidence is lacking we should be wary of dismantling an institution that may be valuable, but better evidence is needed.

B A WhARTON

Consultant Paediatrician,

Children's Programme,

South Birmingham Health Authority,

Birmingham B29 6JD 
1 Langford DM, Stock JM. The Birmingham school meals project. The school meal: the perfect teaching aid. Birmingham: City of Birmingham Education Department, 1977:1-13.

2 Mahoney M. Surrey healthy eating scheme. Food Policy News 1986; No 8:5.

3. Wenlock RW, Disselduff MM, Skinner RK, Knight I. The diets of British schoolchildren. London: HMSO, 1986:1-68.

Department of Health and Social Security. Diet and cardiovascular disease. London: HMSO, 1984. (Report on Health and Social Subjects No 28.)

5 National Advisory Council on Nutrition and Education. Discussion paper on proposals for nutritional guidelines for health education in Britain. London: Health Education Council, 1983.

6 Baker IA, Elwood PC, Hughes J, Jones M, Moore F, Sweetnam P. A randomised controlled trial of the effect of the provision of free school milk on the growth of children. $₹$ Epidemiol Community the effect of the provision

7 Kemm J, Bakshi S, Douglas J, et al. Recommendations for school meals. Nutr Health 1987;4: $237-46$

\section{Deux chevaux, Jaguar-or Ford}

The arguments during the election campaign about the National Health Service seem to have raised awareness (both in the public and among doctors) of the complexities of assessing health care systems. Truly the NHS is a curious entity, since different observers (as in the legend of the blind men and the elephant) seem quite genuinely to perceive it as growing or shrinking, efficient or inefficient, and providing a first or third rate service to patients.

Some of these apparent contradictions can be understood by a close examination of the latest edition of the Compendium of Health Statistics published by the Office of Health Economics. ${ }^{1}$ As a proportion of its gross national product British expenditure on health care (including the NHS, the private sector, and over the counter drugs) has changed hardly at all since 1980 , but in cash terms it has risen dramatically from $£ 12000 \mathrm{~m}$ in 1980 to $£ 20000 \mathrm{~m}$ in 1986 . Nevertheless, when measured against a planned growth rate of $2 \%$ (the national target set in 1980-1) the hospital and community health services have been underfunded by $£ 1325 \mathrm{~m}$ between 1981 and $1986 .^{2}$

Scores of further contrasts appear in the compendium. The number of hospitals in Britain fell from 3027 in 1959 to 2341 in 1985 . Hospital beds declined from 546000 to 404000 in the same period, but the number of nurses for every 1000 beds rose from 348 to 1223 and doctors per 100000 people from 37 to 77 (the variation in the denominators is characteristic of health statistics). Furthermore, the operation of the Resource Allocation Working Party formula has led to variations within Britain in both growth and decline: the four Thames regions used to contain $27 \%$ of the hospital beds in Britain, but by 1985 they contained only $25 \%$.

Out of this bewildering fog of figures some consensus is emerging-right across the political spectrum. The young but flourishing discipline of health economics should take some credit for this, and its leaders are justified in their recent claim that they will have even more to contribute in the next 25 years. ${ }^{3}$ Every Western country is trying to reconcile the continuing growth of consumer demands for health care with limitations on state expenditure. The free market cannot operate freely for one clear reason: the individuals most likely to need medical care are those least likely to be able to afford it-the poor and the elderly. In all countries the state is funding an increasing proportion of the care for patients in these categories. (One example close to home is that $82 \%$ of NHS drug prescriptions now fall into one or other exempt category.)

The gap on to which attention is now focused, as Sir Brian Thwaites explained last month, ${ }^{45}$ is between the public's expectations and the resources that are available, and this gap seems certain to grow despite efforts to introduce rationing. The question that doctors should now be addressing is how wide the expectation/disenchantment gap should be-and how it can be narrowed. ${ }^{5}$ This week the BMA has joined with the Royal College of Nursing and the Institute of Health Services Management in proposing that expenditure on the NHS should be linked to economic growth so that its funding should rise in line with the nation's wealth (p 1695). ${ }^{6} \mathrm{Next}$ week the BMA's annual representative meeting will be giving priority to several motions calling for a re-examination of ways of funding the NHS.?

Doctors should not be too modest in arguing the case for more state money for health. The economists tell us, rightly, that the countries that spend most on health care are the richest, such as Germany and the United States. Yet in Europe the countries with gross national products closest to ours-Belgium, Austria, The Netherlands, and France-all spend more on health, and The Netherlands and France spend $60 \%$ more (around $£ 590$ a head as opposed to our $£ 364$ in 1985). As Nicholas Timmins pointed out last week in a perceptive article in the Independent ${ }^{8}$ a substantial factor in that increased spending is the cost of administration of a health insurance system. Yet surely health care could get a truly bigger slice of the national cake by spreading the sources of income wider so that the government, employers, and citizens all contribute. And to suggest modelling health care on a Dutch pattern does not betray the principles of the NHS; in The Netherlands there is, in effect, a single standard of health care available to the whole population funded by health insurance with no one excluded.

At present Britain has the cheapest (and possibly the most cost effective) health system in Western Europe. Most citizens have no choice on where to go for medical emergencies, chronic illnesses, or high technology treatments: they rely on the NHS. Private practice schemes rarely offer comprehensive care. But in a simple if crude analogy the NHS is priced like the cheapest Citroën car-efficient and reliable but with every possible economy. The private sector offers a few the equivalent of a Jaguar or even a Ferrari. There is nothing in between. Yet in recent years living standards have risen (for those in work), and the opinion polls suggest that many people would like spending on health to rise until it corresponds to, say, a Ford. Is it beyond the ability of politicians and doctors to understand that desire and come up with an answer?

Deputy editor, $B M \mathcal{F}$

TONY SMITH

1 Chew RSB. OHE compendium of health statistics. 6th ed. London: Office of Health Economics, 1987.

2 Anonymous. A rise is a rise is a rise [Editorial]. $\mathrm{Br}$ Med $\mathrm{f}$ 1986:293:290

3 Smith GT, ed. Health economics: prospects for the future. London: Croom Helm, 1987.

Thwaites B. The NHS: the end of the rainbow. Southampton: University of Southampton Institute of Health Policy Studies, 1987.

5 Smith R. The wasted opportunity of the election. BrMed f 1987;294:1438-9.

6 O'Higgins M. Healih spending - a way to sustainable growth. London: Institute of Health Services Management, 1987.

7 British Medical Association. Agenda of annual representative meeting. Br Med $\mathcal{f}$ 1987;294:6 June (insert) (paras 31-39).

8 Timmins N. The defeatism that threatens to paralyse the health service. Independent 1987 June 17:16 (cols 3-7)

\section{Correction}

Asymptomatic carotid stenosis: spare the knife

We regret that an error occurred in the numbering of the references in this leading article by Peter Sandercock ( 30 May, p 1368). In the fourth paragraph the reference number after the sentence "The annual risk of ipsilateral ischaemic thromboembolic stroke may be as low as $0.1 \%$ per year" should have been ${ }^{4}$, not ${ }^{3}$. 